\title{
EVALUATION OF SERUM CREATINE KINASE LEVELS IN PATIENTS WITH HYPOTHYROIDISM
}

\author{
Rekha Nanjundasetty Hemavathi' ${ }^{1}$ Anilkumar Hanumanthaiah ${ }^{2}$
}

${ }^{1}$ Associate Professor, Department of General Medicine, Rajarajeswari Medical College and Hospital. ${ }^{2}$ Associate Professor, Department of General Medicine, Rajarajeswari Medical College and Hospital.

\section{ABSTRACT}

\section{BACKGROUND}

Thyroid disorders are common endocrine disorders. Thyroid function tests which are usually done are measurement of blood levels of hormones Triiodothyronine ( $\mathrm{T}_{3}$ ), Thyroxine $\left(\mathrm{T}_{4}\right)$ and Thyroid Stimulating Hormone (TSH), which are affected by various nonspecific conditions. Therefore, the present study is done to evaluate the role of additional biochemical parameter Creatine Kinase (CK) in diagnosing hypothyroidism. Thyroid function and Creatine Kinase activity was measured in 70 patients with clinically suspected cases of hypothyroidism. Patients with hypothyroidism will have decreased $\mathrm{T}_{3}, \mathrm{~T}_{4}$ levels and increased levels of TSH. However, whether there is any correlation of Creatine Kinase with hypothyroidism is not well established. In our study, we found that in hypothyroid patients there is significant increase in CK levels. Measurement of CK levels is an additional biochemical parameter to diagnose hypothyroidism.

\section{KEYWORDS}

Creatine Kinase, Hypothyroidism.

HOW TO CITE THIS ARTICLE: Hemavathi RN, Hanumanthaiah A. Evaluation of serum creatine kinase levels in patients with hypothyroidism. J. Evolution Med. Dent. Sci. 2016;5(35):2053-2055, DOI: 10.14260/jemds/2016/481

\section{INTRODUCTION}

Thyroid gland is located in the neck, anterior to the trachea. It consists of two lobes that are connected by an isthmus. The gland produces hormones which play a great role in the control of Basal Metabolic Rate (BMR), general body metabolism, growth, development and tissue differentiation. ${ }^{1}$ Overt abnormalities in thyroid function are common endocrine disorder affecting $5-10 \%$ of individual over a lifespan. Clinical symptoms and signs are often nonspecific. The diagnosis and monitoring of therapy depends crucially on measurement of thyroid hormones. ${ }^{2}$

The commonly used parameters for assessment of thyroid function are estimation of $\mathrm{TSH}_{3} \mathrm{~T}_{3}, \mathrm{~T}_{4}$, free $\mathrm{T}_{3}$ and free $\mathrm{T}_{4}$. TSH has been accepted as the initial screening test. The abnormal TSH levels necessitates the use of other indicators of thyroid status. However, none of these parameters have been proven to be ideal because levels may vary in conditions like pregnancy, use of oral contraceptives, protein wasting diseases, liver diseases and drugs. The inherent limitations of these parameters necessitate the establishment of additional markers and enzymes like transaminases, lactate dehydrogenase and Creatine Kinase (CK). Among these creatine kinase has shown promising results as a diagnosing tool for further thyroid disease.

Serum Creatine Kinase (CK) was first used as diagnostic aid in progressive muscular dystrophy in 1959. Since then it has become important clinical marker for muscle damage. The serum CK levels in healthy individual depend on age, race, lean body mass and physical activity. ${ }^{3}$

Financial or Other, Competing Interest: None.

Submission 11-02-2016, Peer Review 14-04-2016,

Acceptance 18-04-2016, Published 02-05-2016.

Corresponding Author:

Dr. Rekha Nanjundasetty Hemavathi,

Associate Professor,

Department of General Medicine,

Rajarajeswari Medical College and Hospital,

Bangalore-560074.

E-mail: drrekhanh@gmail.com

DOI: $10.14260 /$ jemds $/ 2016 / 481$
Musculoskeletal disorders often accompany thyroid dysfunction. They are much more common in hypothyroidism patients. Skeletal muscle is affected more profound in patients with overt hypothyroidism.4,5 Several studies have been conducted to establish a relationship of CK activity in hypothyroidism. However, the correlation between CK activity and circulating concentrations of $\mathrm{T}_{3}, \mathrm{~T}_{4}$, TSH has not been established consistently. The aims of this study is to determine serum activities of $\mathrm{CK}$ levels in patients with overt hypothyroidism and to evaluate the relationship between TSH, $\mathrm{T}_{3}$ levels and degree of skeletal muscle involvement in these thyroid disorders.

\section{MATERIALS AND METHODS}

The study was done at Rajarajeswari Medical College and Hospital, Bangalore. This is an observational clinical study.

The study group comprised of 69 patients presenting with clinical symptoms suggestive of hypothyroidism, both in patients and outpatients were included in the study; 57 patients with age, sex matched controls were taken randomly with no symptoms.

Patients with previous use of L-Thyroxine or antithyroid medications, thyroidectomy, patients with history of recent fall, intoxication, intramuscular injection, seizure, stroke, excessive physical exercise and patients on medications like antiarrhythmics, beta-blockers, lithium, fibrates, phenothiazines, steroids, statins were excluded from the study. Institutional Ethical Committee permission was taken before the study. Data collected was subjected to standard statistical analysis.

All the patients were screened for detail clinical history, drug history especially which affect CK and thyroid hormone levels. Informed written consent was obtained for venepuncture. The fasting venous blood samples were collected by standard aseptic techniques. Serum was separated and assays were performed. Serum $\mathrm{T}_{3}, \mathrm{~T}_{4}$ and $\mathrm{TSH}$ were measured by competitive Enzyme Linked Immune Sorbent Assay (ELISA). TSH was measured by quantitative ELISA using Monobind kits. 
Serum CK activity was measured by modified International Federation of Clinical Chemistry (IFCC) method.

\section{RESULTS}

The present study was_conducted to evaluate the levels of CK in the hypothyroid patients. The serum CK levels of study group and control group were compared (Table 1) and correlation between $\mathrm{T}_{3}$ and CK levels. The mean values of $\mathrm{T}_{3}$ and $\mathrm{T}_{4}$ in case group were 41 and 10 respectively. Mean TSH in hypothyroid patients was 76 . The mean values of $\mathrm{T}_{3}, \mathrm{~T}_{4}$ and TSH in control group were 140.8, 12.3 and 2.84 respectively (Table 2). The mean CK in hypothyroid patients was 416 and mean CK in controls was 90. Serum CK levels was elevated in $71 \%$ of cases compared to controls $1.8 \%$. Serum CK levels was elevated in patients with low $\mathrm{T}_{3}$ levels $(\mathrm{p}<0.001)$. There was negative correlation between CK levels and serum $\mathrm{T}_{3}$ levels. We also found significant positive correlation between serum CK levels and TSH levels $(\mathrm{p}<0.001)$.

\begin{tabular}{|c|c|c|c|c|}
\hline \multirow{2}{*}{ CPK } & \multicolumn{2}{|c|}{ Cases } & \multicolumn{2}{c|}{ Controls } \\
\cline { 2 - 5 } & No & \% & No & \% \\
\hline Normal & 20 & 29.0 & 56 & 98.2 \\
\hline Abnormal & 49 & 71.0 & 1 & 1.8 \\
\hline Total & $\mathbf{6 9}$ & $\mathbf{1 0 0 . 0}$ & $\mathbf{5 7}$ & $\mathbf{1 0 0 . 0}$ \\
\hline \multicolumn{3}{|c|}{$\begin{array}{c}\text { Table 1: CPK Distribution in Two } \\
\text { Groups of Patients Studied }\end{array}$} \\
\hline
\end{tabular}

$\mathrm{P}<0.001^{* *}$, Significant, Fisher Exact test

\begin{tabular}{|c|c|c|}
\hline Mean Of & Cases & Controls \\
\hline T3 & 41 & 140.7 \\
\hline T4 & 12.5 & 10.3 \\
\hline TSH & 76 & 2.84 \\
\hline CK & 416 & 93.7 \\
\hline \multicolumn{2}{|c|}{ Table 2: Mean Values of T3, T4, TSH and CK } \\
\hline
\end{tabular}

\section{DISCUSSION}

The study was done to evaluate the role of CK as a supportive parameter for diagnosing hypothyroidism. The findings of this study confirms that elevated CK activity is frequently increased in hypothyroidism patients. This study also indicates that CK activity correlates with the degrees of hypothyroidism. Serum Creatine Kinase activity has inverse relationship with thyroid activity. The levels of CK are found to be significantly higher in patients with hypothyroidism as compared to normal individuals. The findings that we found that $71 \%$ of patients with hypothyroidism had elevated CK activities, these findings were in accordance with those of other studies, which report a $43 \%$ to $97 \%$ elevation of serum CK activity in hypothyroidism, Beyer et al $43 \% .{ }^{6}$ Giampietro et al $90 \% .^{7}$ and Soufir et al $97 \% .^{8}$

This increase in CK levels in hypothyroidism is due to various mechanisms. The hypometabolic state of hypothyroidism can cause reduction in glycolysis and oxidative phosphorylation and thus reducing Adenosine Triphosphate (ATP) concentrations. There is alteration in sarcolemmal membrane, which leads to increased cell permeability and leakage of CK from cells. Another possibility is reduced turnover of $\mathrm{CK}$ because of hypothyroid status leads to increased serum CK activity.9,10 Patients with primary hypothyroidism may have myopathy, which is associated with histological changes in muscle cells. This may lead to increase in leakage of the enzyme from the muscle cells. ${ }^{11,12,13}$
Sub-normal body temperature and decrease in enzyme clearance are all responsible for increase in serum $\mathrm{CK}$ activity. 6,14

Hekim Soy et al in 2005 in his study found skeletal muscle is affected more profoundly in cases of overt hypothyroidism. Also there was positive correlation between CK and TSH and negative correlation between $\mathrm{T}_{3}$ and CK levels. ${ }^{4}$

Archna P et al in their study in 2007, there was increase in CK levels in patients with hypothyroidism. There was increase in CK levels in patients with decreased $\mathrm{T}_{3}$ levels. They found serum CK activity showed an inverse relation with thyroid hormones. Panag et al in 2012 in his study on hypothyroid patients found elevated $\mathrm{CK}$ levels in patients compared to controls. A negative correlation was also found between $\mathrm{FT}_{3}$ and CK levels $(\mathrm{p}<0.005)$. $^{3}$

\section{CONCLUSION}

We found there was significant inverse relation between $\mathrm{CK}$ and $\mathrm{T}_{3}$ levels. Thus estimation of serum CK levels will be extremely valuable in screening for hypothyroid patients.

\section{REFERENCES}

1. Panag KMDS, Gitanjali, Sudeep Goyal. Evaluation of creatine kinase as diagnostic tool for thyroid function. IJCP 2012;23(4):221-3.

2. McGrowder DA, Fraser YP, Gordon L. Serum creatine kinase and lactate dehydrogenase activities in patients with thyroid disorders. Nigerian journal of clinical practice 2011;14(4):454-9.

3. Archana P, Lal AK, Negi KS. Serum creatine kinase activity in thyroid disorders. JK science 2007;9(1):25-6.

4. Hekimsoy, Oktem IK. Serum creatine kinase levels in overt and subclinical hypothyroidism. Endo Res 2005;31(3):171-5.

5. Ebashi S, Toyokura T, Momoi H, et al. High creatine phosphokinase activity in sera of progressive muscular dystrophy patients. Bioch J Tokyo 1959;46:103.

6. Beyer IW, Karmali R. Serum creatine kinase levels in overt and subclinical hypothyroidism. Thyroid 1998;8(11):1029-31.

7. Giampietro O, Clerico A, Buzzigoli G. Detection of hypothyroid myopathy by measurements of various serum muscle markers-myoglobin, creatine kinase, lactate dehydrogenase and their isoenzymes. Correlations with thyroid hormone levels (free and total) and clinical usefulness. Horm Res 1984;19(4):232-42.

8. Soufir JC, Zbranca TE, Bernheim R, et al. Assay of serum creatine phosphokinase in primary hypothyroidism. Comparison with other thyroid gland function tests in 32 cases. Value of isoenzyme studies. Nouv Presse Med 1975;4(43):3055-9.

9. Shamali J, Ajay J, Sanjay S. Evaluation of creatine kinase activity as a diagnostic tool for thyroid function. International Journal of Recent Trends in Science And Technology 2013;7(2):60-2.

10. Meltezer HY. Factors affecting creatine kinase levels in the general population. The role of activity, race and age. Clin Chem Acta 1971;33:165-72.

11. O' Malley BP, Davies TJ, Rosenthal FD. Effects of rest, exercise and warming on serum creatine kinase levels in primary hypothyroidism. Clin Sci 1981;60(5):595-7. 
12. Rainsay I. Thyroid disease and muscle dysfunction. London Heinemann Medical Books Ltd 1974.

13. Klein I, Mantell P, Parker M. Resolution of abnormal muscle enzyme in hypothyroidism. Am J Med Sci 1980;279(3):159-63.
14. Khaleeli AA, Griffith DG, Edwards RH. The clinical presentations of thyroid skeletal muscle. Clin Endocrinol 1983;19(3):365-76. 